\title{
Prehospital administration of tranexamic acid in trauma patients
}

\author{
Arasch Wafaisade ${ }^{1 *}$, Rolf Lefering ${ }^{2}$, Bertil Bouillon ${ }^{1}$, Andreas B. Böhmer ${ }^{3}$, Michael Gäßler ${ }^{4}$, Matthias Ruppert ${ }^{4}$ \\ and TraumaRegister DGU
}

\begin{abstract}
Background: Evidence on prehospital administration of the antifibrinolytic tranexamic acid (TXA) in civilian trauma populations is scarce. The aim was to study whether prehospital TXA use in trauma patients was associated with improved outcomes.
\end{abstract}

Methods: The prehospital database of the ADAC (General German Automobile Club) Air Rescue Service was linked with the TraumaRegister of the German Trauma Society to reidentify patients documented in both registries. Primarily admitted trauma patients (2012 until 2014) who were treated with TXA during the prehospital phase were matched with patients who had not received prehospital TXA, applying propensity score-based matching.

Results: The matching yielded two identical cohorts ( $n=258$ in each group), since there were no significant differences in demographics or injury characteristics (mean Injury Severity Score $24 \pm 14$ [TXA] vs. $24 \pm 16$ [control]; $p=0.46$ ). The majority had sustained blunt injury ( $90.3 \%$ vs. $93.0 \% ; p=0.34)$. There were no differences with respect to prehospital therapy, including rates of intubation, chest tube insertion or both administration of i.v. fluids and catecholamines. During ER treatment, the TXA cohort received fewer numbers of red blood cells and plasma units, but without reaching statistical significance. Incidences of organ failure, sepsis or thromboembolism showed no significant differences as well, although data were incomplete for these parameters. Early mortality was significantly lower in the TXA group (e.g., 24-h mortality $5.8 \%$ [TXA] vs. $12.4 \%$ [control]; $p=0.01$ ), and mean time to death was $8.8 \pm 13.4$ days vs. $3.6 \pm 4.9$ days, respectively $(p=0.001)$. Overall hospital mortality was similar in both groups $(14.7 \%$ vs. $16.3 \% ; p=0.72$ ). The most pronounced mortality difference was observed in patients with a high propensity score, reflecting severe injury load.

Conclusions: This is the first civilian study, to our knowledge, in which the effect of prehospital TXA use in trauma patients has been examined. TXA was associated with prolonged time to death and significantly improved early survival. Until further evidence emerges, the results of this study support the use of TXA during prehospital treatment of severely injured patients.

Keywords: Trauma, Bleeding, Coagulopathy, Tranexamic acid

\section{Background}

Exsanguination remains the leading cause of early mortality in trauma patients [1] and recent research has elucidated the role of acute trauma-associated coagulopathy in aggravating haemorrhage [2-4]. Resuscitation strategies for severely injured patients with massive blood loss include several key components, such as transfusion

\footnotetext{
* Correspondence: wafaisadea@kliniken-koeln.de

'Department of Trauma and Orthopedic Surgery, University of Witten/ Herdecke, Cologne-Merheim Medical Center, Ostmerheimer Strasse 200, D-51109 Cologne, Germany

Full list of author information is available at the end of the article
}

of blood components to reestablish perfusion and coagulation function [5]. Furthermore, several commercially available haemostatic agents are commonly applied as adjuncts to support coagulation [6]. Since clot degradation by early hyperfibrinolysis has been reported to play a major role in traumatic coagulopathy and massive bleeding, recent clinical research has been focused on the antifibrinolytic substance tranexamic acid (TXA) [7]. However, only one large randomised controlled trialClinical Randomisation of an Antifibrinolytic in Significant Haemorrhage 2 (CRASH-2) - has examined the effect of 
in-hospital TXA administration in trauma, but the results have been discussed controversially due to several weaknesses of the trial, such as that the majority of patients were enrolled in developing countries [8, 9]. Altogether, evidence on prehospital TXA use in trauma, especially from European countries, is scarce. Accordingly, existing guidelines either provide no statement or make only a weak recommendation to consider en route administration of TXA [10]. However, since no other drug is approved for coagulation support during prehospital treatment, the aim of the present study was to assess whether prehospital intravenous (i.v.) administration of TXA in trauma patients is associated with improved outcomes.

\section{Methods}

\section{General German Automobile Club Air Rescue Service database}

The General German Automobile Club (ADAC) Air Rescue Service operates 35 air ambulance helicopters throughout Germany and is therefore the largest national provider of Air Rescue Services. For each rescue mission and each patient, information on the prehospital course and treatment is documented including air rescue-specific parameters [11]. The severity of illness and/or injury is assessed by applying the National Advisory Committee for Aeronautics (NACA) score, ranging from I (minor disturbance/injury) to VII (death) [12]. As the equipment for each helicopter regarding medication is regulated according to its respective local policies, TXA has been provided by 20 of the 35 Air Rescue helicopters during the 3-year study period. Patients were treated with TXA at the discretion of the emergency physician.

\section{TraumaRegister DGU ${ }^{\circledR}$}

The TraumaRegister DGU ${ }^{\bullet}$ (TR-DGU) of the German Trauma Society (Deutsche Gesellschaft für Unfallchirurgie, DGU) was founded in 1993 [13]. The aim of this multicentre database is an anonymous and standardized documentation of severely injured patients. Data are collected prospectively in four consecutive time phases from the site of the accident until discharge from the hospital: (A) prehospital phase, (B) emergency room (ER) and initial surgery, (C) intensive care unit (ICU) and (D) discharge. The documentation includes detailed information on demographics, injury patterns, comorbidities, pre- and in-hospital management, course on the ICU, relevant laboratory findings including data on transfusions, and outcomes of each individual.

The participating hospitals are located primarily in Germany (90\%), but a rising number of hospitals in other countries contribute data as well (e.g., Austria, Belgium, Finland, Luxembourg, Slovenia, Switzerland). Currently, approximately 25,000 cases per year from more than 600 hospitals are entered into the database.
The documentation comprises detailed information including standardized scoring systems (e.g., the Injury Severity Score [ISS]) [14]. All injuries are coded using the Abbreviated Injury Scale [15]. Organ failure was assessed using the Sequential Organ Failure Assessment score [16]. Sepsis was defined according to the Bone criteria, which are close to those of the American College of Chest Physicians/Society of Critical Care Medicine consensus conference definition [17]. The TR-DGU documents the prothrombin time as prothrombin time index (expressed as a percentage of normal; also commonly referred to as Quick's test), where a value of $<70 \%$ corresponds to an international normalized ratio $>1.3[3,18]$.

\section{Study population}

Due to data security and confidentiality, both databases provide anonymized data; thus, there was no information available about whether individual patients were included in these two independent databases in parallel. As the ADAC Air Rescue Service registry is limited to the prehospital setting without providing information on the patient's in-hospital course, and since the TR-DGU does not document the prehospital administration of TXA, we linked the data to reidentify patients documented in both registries. Patient records from both databases collected between 1 January 2012 and 31 December 2014 were considered for the present study (Fig. 1).

Patients were included in this study according to the following criteria:

1. ADAC Air Rescue Service database:

a. Primarily admitted trauma patient

b. Critical injury, defined as preclinically assessed NACA IV (potentially life-threatening), NACA V (acute danger) or NACA VI (respiratory and/or cardiac arrest)

c. Admission to a trauma centre participating in the TR-DGU

2. TR-DGU database:

a. Primary admission

b. Treatment in a German trauma centre (i.e., exclusion of trauma centres from other countries)

Data were linked using the parameters age, sex, date and time of injury, and trauma centre (Fig. 1). Thus, a total of 5765 patients were identified as documented in both databases, of whom 258 patients had received i.v. administration of TXA before ER arrival. These 5765 patients were eligible for propensity score-based matchedpairs analysis. A multivariable analysis was conducted using a logistic regression model with prehospital administration of TXA as a dependent variable (Table 1). The resulting independent predictors were applied to calculate 


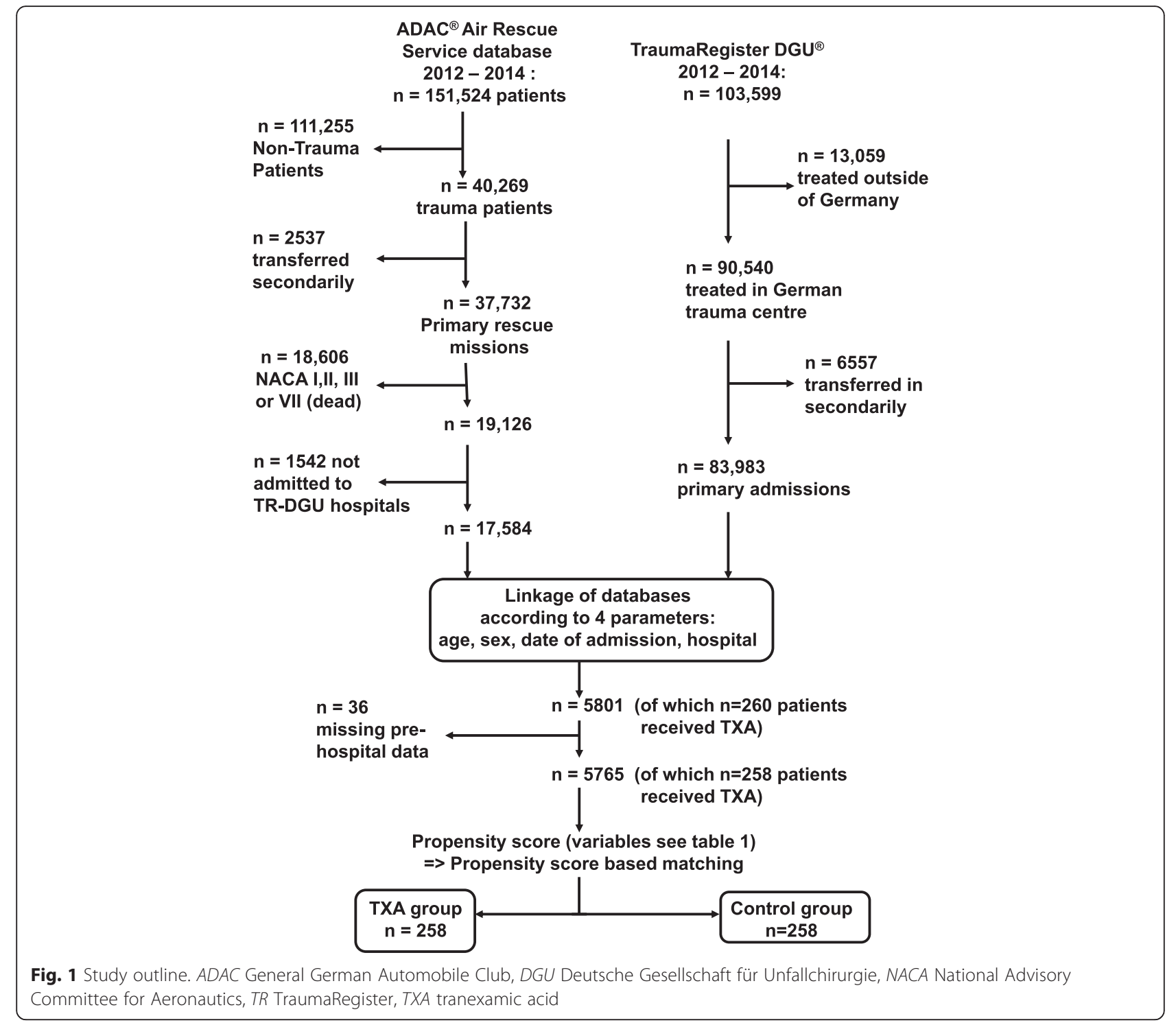

a propensity of receiving prehospital TXA. Each of the 258 TXA patients was matched with 1 of the 5507 control patients according to the propensity of receiving TXA; for example, a patient with a propensity of $7 \%$ was matched with another patient with a $7 \%$ propensity. Matching was performed blinded to outcome.

\section{Study approval}

The medical authorities of the ADAC Air Rescue Service and the scientific committee of the TR-DGU approved the design and publication of this study. This study and publication are in line with the publication guidelines of the TraumaRegisterDGU ${ }^{\circ}$ and registered as TR-DGU project ID 2015-023. The present study was also approved by the ethics committee of the Faculty of Medicine, University of Witten/Herdecke (Alfred-Herrhausen-Strasse 50, 58448 Witten, Germany; register number 85/2015).

\section{Statistical analysis}

Data were compared between groups using the MannWhitney $U$ test for continuous variables and Fisher's exact test for categorical variables, if not indicated otherwise. For comparison of the Kaplan-Meier survival curves, the Mantel-Cox log-rank test was applied. Data are presented as mean with standard deviation $( \pm S D)$ for continuous variables and as percentages for incidence rates. We applied a significance level $p<0.05$ to all statistical tests. Statistical analysis was performed using standard statistical software (SPSS version 18.0 software; SPSS, Chicago, IL, USA).

\section{Results}

Among the 5765 patients with complete datasets, 258 pairs with corresponding propensity of TXA administration were identified. As intended, the matching yielded 
Table 1 Multivariable analysis using a logistic regression model with prehospital administration of tranexamic acid as a dependent variable $(n=5765)$

\begin{tabular}{|c|c|c|c|}
\hline Variable entered & $\begin{array}{l}\text { Regression } \\
\text { coefficient } \beta\end{array}$ & OR $\left(e^{\beta} ; 95 \% \mathrm{Cl}\right)$ & $p$ Value \\
\hline $\begin{array}{l}\text { Isolated TBI } \\
\text { (AlS head } \geq 3 \text { ) }\end{array}$ & -1.009 & $0.365(0.165-0.806)$ & 0.013 \\
\hline AlS $_{\text {thorax }} \geq 3$ & -0.282 & $0.755(0.570-0.998)$ & 0.049 \\
\hline $\mathrm{AlS}_{\text {abdomen }} \geq 3$ & 0.524 & $1.689(1.212-2.355)$ & 0.002 \\
\hline AIS $_{\text {extremities }} \geq 3$ & 0.346 & $1.414(1.078-1.854)$ & 0.012 \\
\hline Intubation prehospital & 1.043 & $2.837(2.022-3.981)$ & $<0.001$ \\
\hline Chest tube prehospital & 0.506 & $1.658(1.093-2.516)$ & 0.017 \\
\hline Penetrating injury & 0.369 & $1.446(0.970-2.157)$ & 0.070 \\
\hline $\begin{array}{l}\text { Prehospital i.v. } \\
\text { fluids } \geq 1000 \mathrm{ml}\end{array}$ & 0.147 & 1.159 (0.980-1.370) & 0.085 \\
\hline \multicolumn{4}{|l|}{$\begin{array}{l}\text { Initial systolic } \\
\text { blood pressure }\end{array}$} \\
\hline$>110 \mathrm{mmHg}$ & Reference & & 0.193 \\
\hline $81-110 \mathrm{mmHg}$ & -1.164 & $0.312(0.074-1.321)$ & 0.114 \\
\hline $1-80 \mathrm{mmHg}$ & 0.244 & $1.276(0.843-1.930)$ & 0.249 \\
\hline $0 \mathrm{mmHg}$ & 0.141 & $1.152(0.849-1.563)$ & 0.364 \\
\hline Age $\geq 60$ years & -0.397 & $0.672(0.477-0.947)$ & 0.023 \\
\hline $\begin{array}{l}\text { Prehospital GCS } \\
\text { score } \leq 8\end{array}$ & -0.166 & $0.847(0.630-1.140)$ & 0.275 \\
\hline Constant* & -3.791 & 0.023 & $<0.001$ \\
\hline
\end{tabular}

AIS Abbreviated Injury Scale, GCS Glasgow Coma Scale, i.v. intravenous, $T B I$ traumatic brain injury

The reference category is included in brackets behind the variable name and does not receive a coefficient in the model. ORs have to be interpreted in relation to this standard category

*The constant in a logistic model provides a basic risk that applies to the case that all other coefficients are zero

two similar cohorts, as there were no significant differences in demographic data, injury characteristics or prehospital course between treatment groups (Table 2). Patients were predominantly male, and their average ages by group were $43 \pm 19$ years (TXA group) vs. $41 \pm 18$ years (control group) $(p=0.48)$. The mean ISSs for the TXA and control groups were $24 \pm 14$ and $24 \pm 16$, respectively $(p=0.46)$, and the majority had sustained a blunt injury ( $90.3 \%$ vs. $93.0 \%$, respectively; $p=0.34$ ). There were also no differences with respect to injury pattern, prehospital vital signs and prehospital therapy, including rates of intubation, chest tube insertion, cardiopulmonary resuscitation and administration of both i.v. fluids and catecholamines. Table 3 summarizes the vital signs and laboratory values upon ER admission, showing no significant differences as well. Before ICU admission, the TXA cohort received fewer numbers of packed red blood cells $(\mathrm{pRBC})$ and plasma units, but without reaching statistical significance. Further haemostatic agents were applied in similar frequencies as well, including fibrinogen concentrate.
Table 2 Demographic and prehospital characteristics of trauma patients (2012-2014) with and without tranexamic acid administered during the prehospital phase

\begin{tabular}{|c|c|c|c|}
\hline & $\begin{array}{l}\text { Tranexamic acid } \\
(\text { TXA) group } \\
(n=258)\end{array}$ & $\begin{array}{l}\text { Control group } \\
(n=258)\end{array}$ & $p$ Value \\
\hline Age, years, mean $\pm S D$ & $43 \pm 19$ & $41 \pm 18$ & 0.48 \\
\hline Male sex, $n(\%)$ & $187(72.5)$ & $187(72.5)$ & 1.00 \\
\hline Traffic accident, $n$ (\%) & $180(69.8)$ & $189(73.3)$ & 0.44 \\
\hline Blunt trauma, n (\%) & $233(90.3)$ & $240(93.0)$ & 0.34 \\
\hline ISS, points, mean \pm SD & $24 \pm 14$ & $24 \pm 16$ & 0.46 \\
\hline $\mathrm{AIS}_{\text {head }} \geq 3, n(\%)$ & $89(34.5)$ & $95(36.8)$ & 0.65 \\
\hline $\mathrm{AlS}_{\text {thorax }} \geq 3, n(\%)$ & $120(46.5)$ & $125(48.4)$ & 0.72 \\
\hline $\mathrm{AIS}_{\text {abdomen }} \geq 3 n(\%)$ & $54(20.9)$ & $47(18.2)$ & 0.51 \\
\hline $\mathrm{AIS}_{\text {extremities }} \geq 3, n(\%)$ & $114(44.2)$ & $112(43.4)$ & 0.93 \\
\hline $\begin{array}{l}\text { Isolated TBI, } \mathrm{AIS}_{\text {head }} \geq 3 \text {, } \\
n(\%)\end{array}$ & $7(2.7)$ & $8(3.1)$ & 0.94 \\
\hline $\begin{array}{l}\text { SBP at scene } \leq 90 \mathrm{mmHg} \text {, } \\
n(\%)\end{array}$ & $55(21.3)$ & $54(20.9)$ & 1.0 \\
\hline $\begin{array}{l}\mathrm{SBP} \text { at scene, } \mathrm{mmHg} \text {, } \\
\text { mean } \pm \mathrm{SD}\end{array}$ & $118 \pm 34$ & $116 \pm 33$ & 0.36 \\
\hline GCS at scene $\leq 8, n(\%)$ & $89(34.5)$ & $96(37.2)$ & 0.58 \\
\hline $\begin{array}{l}\text { GCS at scene, points, } \\
\text { mean } \pm \text { SD }\end{array}$ & $10.5 \pm 4.9$ & $10.2 \pm 5.0$ & 0.69 \\
\hline \multicolumn{4}{|l|}{ Prehospital treatment } \\
\hline Intubation, n (\%) & $193(74.8)$ & $195(75.6)$ & 0.92 \\
\hline Chest tube insertion, $n(\%)$ & $34(13.2)$ & $28(10.9)$ & 0.50 \\
\hline CPR, n (\%) & $11(4.3)$ & $8(3.1)$ & 0.64 \\
\hline Catecholamines, $n(\%)$ & $44(17.1)$ & $50(19.4)$ & 0.57 \\
\hline i.v. Fluids, ml, mean \pm SD & $1140 \pm 760$ & $1181 \pm 919$ & 0.84 \\
\hline $\begin{array}{l}\text { Duration of prehospital phase, } \\
\text { minutes, mean } \pm S D\end{array}$ & $77.2 \pm 25.0$ & $74.2 \pm 25.1$ & 0.22 \\
\hline Air transport, $n(\%)$ & $210(81.4)$ & $203(78.7)$ & 0.51 \\
\hline
\end{tabular}

AIS Abbreviated Injury Scale, CPR cardiopulmonary resuscitation, GCS Glasgow Coma Scale, i.v. intravenous, ISS Injury Severity Score, SBP systolic blood pressure, $S D$ standard deviation, $T B /$ traumatic brain injury

Data for all 516 patients were documented for the parameters of this table

The outcome parameters (Table 4) showed no differences with respect to incidence of multiple organ failure, sepsis or thromboembolism, although for these parameters data were not documented for the complete study population.

Early mortality was significantly lower in the TXA group (e.g., 24-h mortality $5.8 \%$ [TXA] vs. $12.4 \%$ [control]; $p=0.01)$, and mean time to death was $8.8 \pm 13.4$ days (TXA) vs. $3.6 \pm 4.9$ days (control) $(p=0.001)$. Overall hospital mortality was similar in both groups $(14.7 \%$ vs. $16.3 \% ; p=0.72)$. Correspondingly, these mortality rates are reflected in the survival curves, since for the initial days following ER arrival TXA patients tended to have higher survival (Fig. 2). The log-rank test yielded no significant differences for these Kaplan-Meier plots $(p=0.47)$. 
Table 3 Clinical characteristics upon emergency room admission of trauma patients (2012-2014) with and without tranexamic acid administered during the prehospital phase

\begin{tabular}{|c|c|c|c|}
\hline & Tranexamic acid (TXA) group & Control group & $p$ Value \\
\hline $\mathrm{SBP}$ at $\mathrm{ER} \leq 90 \mathrm{mmHg}, n(\%)$ & $51 / 236(21.6)$ & $50 / 247(20.2)$ & 0.74 \\
\hline $\mathrm{SBP}$ at $\mathrm{ER}, \mathrm{mmHg}$, mean $\pm \mathrm{SD}(n)$ & $114 \pm 27(236)$ & $117 \pm 32(247)$ & 0.19 \\
\hline Haemoglobin, ${ }^{a} \mathrm{~g} / \mathrm{dl}$, mean $\pm \mathrm{SD}(n)$ & $11.7 \pm 2.8(239)$ & $11.4 \pm 2.8(227)$ & 0.33 \\
\hline Base excess, ${ }^{a}$ mmol/L, mean \pm SD $(n)$ & $-3.1 \pm 4.7(221)$ & $-3.5 \pm 5.1(219)$ & 0.38 \\
\hline $\mathrm{INR}^{\mathrm{a}}$ mean $\pm \mathrm{SD}(n)$ & $1.3 \pm 0.7(230)$ & $1.3 \pm 0.5(216)$ & 0.53 \\
\hline PTI, ${ }^{a}$ Quick's test points, mean \pm SD $(n)$ & $76 \pm 22(230)$ & $75 \pm 23(216)$ & 0.57 \\
\hline i.v. Fluids, ${ }^{b} \mathrm{ml}$, mean $\pm \mathrm{SD}(n)$ & $1945 \pm 2889$ & $1867 \pm 2005(146)$ & 0.46 \\
\hline Crystalloids, ${ }^{\mathrm{b}} \mathrm{ml}$, mean $\pm \mathrm{SD}(n)$ & $1668 \pm 2421(182)$ & $1523 \pm 1817(146)$ & 0.92 \\
\hline Colloids, ${ }^{b} \mathrm{ml}$, mean $\pm \mathrm{SD}(n)$ & $249 \pm 591(182)$ & $317 \pm 556(146)$ & 0.18 \\
\hline pRBC transfusion, ${ }^{b} n(\%)$ & $64 / 258(24.8)$ & $65 / 258(25.2)$ & 1.00 \\
\hline pRBC units, ${ }^{b}$ mean $\pm S D(n)$ & $1.6 \pm 4.3(258)$ & $2.0 \pm 5.8(258)$ & 0.81 \\
\hline Number of units if given, mean $\pm S D /$ median & $6.6 \pm 6.5 / 4$ & $7.8 \pm 9.4 / 4$ & 0.81 \\
\hline FFP transfusion, ${ }^{b} n(\%)$ & $40 / 258(15.5)$ & $43 / 258(16.7)$ & 0.81 \\
\hline FFP units, ${ }^{b}$ mean \pm SD $(n)$ & $1.2 \pm 3.8(258)$ & $1.4 \pm 4.6(258)$ & 0.68 \\
\hline Number of units if given, mean $\pm S D /$ median & $7.7 \pm 6.7 / 6$ & $8.4 \pm 8.1 / 5$ & 0.68 \\
\hline Platelet transfusion, ${ }^{\mathrm{b}}$ n (\%) & $8 / 258(3.1)$ & $12 / 256(4.7)$ & 0.37 \\
\hline Platelet units, ${ }^{\mathrm{b}}$ mean $\pm \mathrm{SD}(n)$ & $0.1 \pm 0.7(258)$ & $0.1 \pm 0.9(256)$ & 0.37 \\
\hline Number of units if given, mean $\pm \mathrm{SD} /$ median & $3.8 \pm 2.1 / 3.5$ & $2.9 \pm 3.0 / 2$ & 0.37 \\
\hline Massive transfusion, ${ }^{\mathrm{b}} \geq 10 \mathrm{pRBC}, n(\%)$ & $13 / 258(5.0)$ & $15 / 258(5.8)$ & 0.85 \\
\hline Haemostatic drugs, $n$ (\%) & $36 / 205(17.6)$ & $35 / 149(23.5)$ & 0.18 \\
\hline Fibrinogen concentrate, $\mathrm{n}(\%)$ & 26/205 (12.7) & 24/149 (16.1) & 0.44 \\
\hline Level 1 trauma centre, $n(\%)$ & $182 / 258(70.5)$ & $200 / 258(77.5)$ & 0.09 \\
\hline
\end{tabular}

ER emergency room, FFP fresh frozen plasma, i.v. intravenous, INR international normalized ratio, $p R B C$ packed red blood cells, SD standard deviation As some values were missing, the respective population is presented in the denominator for continuous variables and in brackets for categorical variables a Laboratory values measured upon emergency room arrival

${ }^{b}$ pRBC, FFP, intravenous fluids and haemostatic drugs administered between emergency room arrival and intensive care unit admission

In a subgroup analysis, Fig. 3 illustrates that the most pronounced decrease in mortality from TXA could be observed in those patients with a high propensity score, with the score indicating a more complicated prehospital course and higher injury severity as reflected by the factors derived from multivariate analysis shown in Table 1.

\section{Discussion}

To our knowledge, this is the first civilian study to examine the effect of prehospital TXA use in trauma patients. Our propensity score-based matched-pairs analysis of a large population of trauma patients resulted in two identical groups, and the prehospital i.v. administration of TXA was associated with a significantly lower early mortality (up to $24 \mathrm{~h}$ ) and increased time to death. Particularly those patients appeared to benefit most from TXA who had a high propensity score reflecting severe injury load. The improvement of early outcome may suggest benefits of TXA on haemostatic resuscitation, since previous investigations have indicated that the majority of deaths due to traumatic bleeding occur in the first few hours following trauma [19]. In this context, the recent Pragmatic Randomized Optimal Platelet and Plasma Ratios trial showed that exsanguination was the predominant cause of death within the first $24 \mathrm{~h} \mathrm{[5].}$

However, although the amount of blood components was lower in the TXA group, the difference was not significant. Surprisingly, only about $25 \%$ in both groups required any transfusion at all. The lower mortality rates may also be explained by the anti-inflammatory effects of TXA [20], although further studies are required to elucidate this potential additional benefit. Multiple randomised controlled trials from elective surgery (e.g., orthopaedic, cardiovascular) have shown beneficial effects of TXA with respect to reduced perioperative blood loss [21]. Still, to date, CRASH-2 represents the only randomised controlled trial on TXA in trauma [8]. The researchers in that study recruited 20,211 trauma patients following hospital admission and showed that treatment with TXA significantly reduced all-cause mortality vs. placebo (14.5\% vs. $16.0 \%)$. Death caused by haemorrhage was reduced as well $(4.9 \%$ vs. $5.7 \%)$, 
Table 4 Outcome data

\begin{tabular}{|c|c|c|c|}
\hline & $\begin{array}{l}\text { Tranexamic acid } \\
\text { (TXA) group }\end{array}$ & Control group & $p$ Value \\
\hline $\begin{array}{l}\text { ICU LOS, days, } \\
\text { mean } \pm \text { SD }(n)\end{array}$ & $10.7 \pm 12.6(258)$ & $9.2 \pm 11.4(258)$ & 0.03 \\
\hline $\begin{array}{l}\text { Hospital LOS, days, } \\
\text { mean } \pm \mathrm{SD}(n)\end{array}$ & $25.5 \pm 23.2(258)$ & $22.3 \pm 25.4(258)$ & 0.04 \\
\hline $\begin{array}{l}\text { Thromboembolic } \\
\text { event, } n(\%)\end{array}$ & 4/71 (5.6) & 10/121 (8.3) & 0.58 \\
\hline Sepsis, $n$ (\%) & $4 / 67(6.0)$ & $8 / 119(6.7)$ & 1.00 \\
\hline $\begin{array}{l}\text { Multiple organ } \\
\text { failure, } n(\%)\end{array}$ & $27 / 74(36.5)$ & 35/121 (28.9) & 0.34 \\
\hline $\begin{array}{l}\text { Time to death, days, } \\
\text { mean } \pm \text { SD }(n)\end{array}$ & $8.8 \pm 13.4(258)$ & $3.6 \pm 4.9(258)$ & 0.001 \\
\hline 6-h mortality, n (\%) & $5 / 258(1.9)$ & 24/258 (9.3) & $<0.001$ \\
\hline 12-h mortality, $n$ (\%) & $9 / 258(3.5)$ & 28/258 (10.9) & 0.002 \\
\hline 24-h mortality, n (\%) & 15/258 (5.8) & $32 / 258(12.4)$ & 0.01 \\
\hline 30-day mortality, n (\%) & 36/258 (14.0) & $42 / 258(16.3)$ & 0.54 \\
\hline $\begin{array}{l}\text { In-hospital mortality } \\
\text { overall, } n(\%)\end{array}$ & 38/258 (14.7) & $42 / 258(16.3)$ & 0.72 \\
\hline $\begin{array}{l}\text { Mortality prognosis in \%, } \\
\text { based on RISC } 2 \text { score (n) }\end{array}$ & $15.4 \%(258)$ & $15.2 \%(258)$ & 0.38 \\
\hline
\end{tabular}

ICU intensive care unit, LOS length of stay, RISC Revised Injury Severity Classification, $S D$ standard deviation

As some values were missing, the respective population is documented in brackets for continuous variables and in the denominator for categorical variables without increasing thromboembolic events. The authors of a post hoc analysis observed beneficial effects, especially when TXA was given early (within $1 \mathrm{~h}$ after trauma), and delayed administration was even linked with worse outcomes [9]. However, several weaknesses and gaps of CRASH-2 have been discussed controversially [22]. First, data on laboratory values, on injury severity or on subtypes of transfused blood components ( $\mathrm{pRBC}$, fresh frozen plasma) were not reported. Second, the majority of patients were enrolled in low-income or developing countries, causing hesitancy to translate the findings to mature trauma systems. Retrospective military studies (Military Application of Tranexamic Acid in Trauma Emergency Resuscitation [MATTERs]) from a combat treatment facility in southern Afghanistan confirmed the benefits of TXA in battle casualties [23, 24]. The evidence from developed countries remains equivocal. In a single-centre retrospective analysis done in Miami, FL, USA, TXA was administered at a median of 97 minutes following ER admission to 150 patients deemed to be at high risk for haemorrhagic death. Propensity score-based matching demonstrated higher mortality in the TXA group [25]. In another single-centre study, done in London, UK, the majority of patients $(n=160)$ received TXA in the ER during the adoption phase of a major haemorrhage protocol [26]. However, this cohort was also more severely injured and more coagulopathic than non-TXA patients, since TXA was administered when critical injury or signs of haemorrhagic shock were present. Still, multivariate adjustments suggested potential benefits in severely injured shock patients. Furthermore, Moore et al. demonstrated that only a

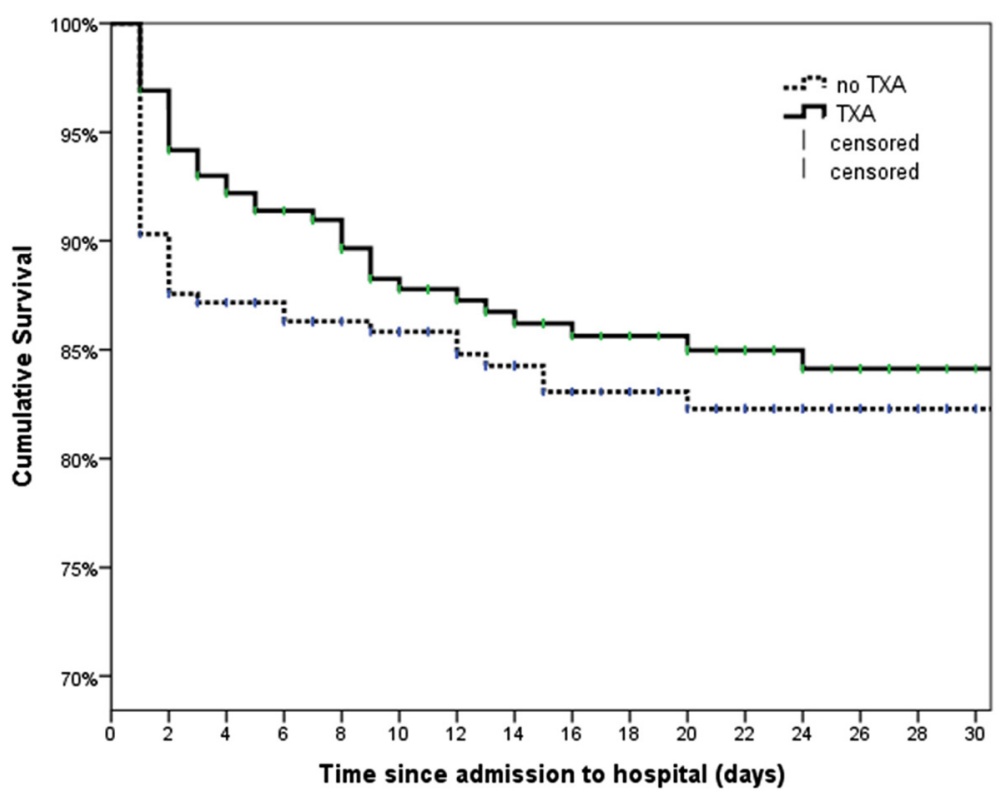

Fig. 2 Kaplan-Meier survival rates up to 30 days following hospital admission. Data were censored in case of discharge or transfer. $p=0.472$ (log-rank test). TXA tranexamic acid 


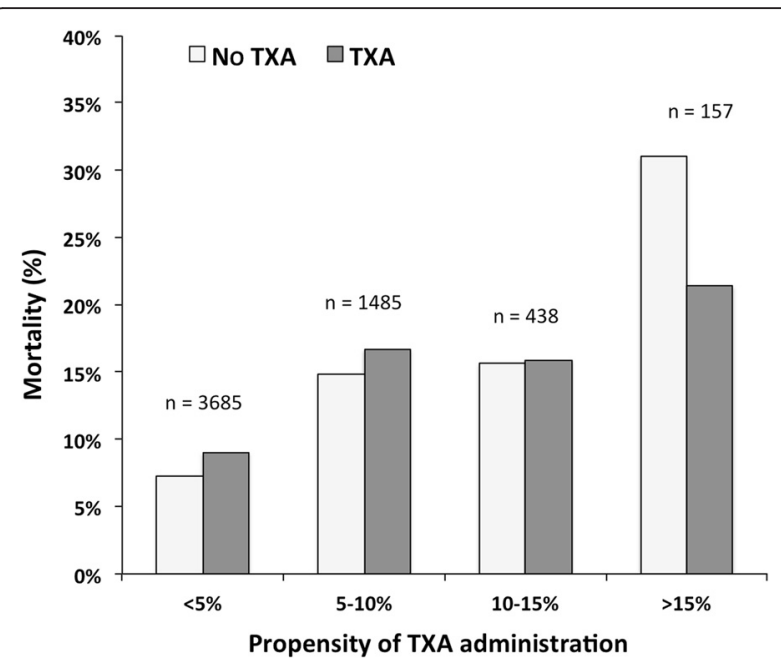

Fig. 3 Mortality rates for patients with $(n=258)$ and without $(n=5507)$ TXA treatment in groups with increasing propensity of TXA administration $\left(p<0.001, X^{2}\right.$ test). Propensity of TXA administration was calculated by applying the predictors derived from Table 1. TXA tranexamic acid

minority of severely injured patients presented with hyperfibrinolysis upon admission and a majority even displayed shut-down of fibrinolysis, raising concerns that TXA might cause complications in these patients [7]. Although CRASH-2 showed no difference with respect to vascular occlusive events, the authors admitted that, owing to trial design, they "might have underreported the frequency of these events" [8]. In the MATTERs study, TXA was associated with higher rates of thromboembolic events [23]. In our study, we found no difference, but data were incomplete. However, longer ICU stay and longer hospital stay in our TXA group might indicate a more complicated course.

The decision of several ADAC air rescue bases against TXA use reflects both the ongoing controversy regarding TXA and the uncertainty with applying a substance that has such weak evidence in the prehospital phase. In a recent review, Ausset et al. summarized that the evidence for the prehospital use of TXA regarding trauma populations is lacking [27]. Several groups have simply published their experience with the feasibility and frequency of prehospital TXA administration, but without reporting any outcome data [28-31].

Several limitations of the present study must be addressed. First, laboratory parameters with respect to hyperfibrinolysis or inflammation (e.g., D-dimers, thromboelastometry, interleukin-6) are not available in the databases. Second, the documentation of data was incomplete and inconsistent with respect to morbidity (organ failure, sepsis, thromboembolism). Furthermore, as the two databases were merged, only 5801 of 17,584 patients in the ADAC Air Rescue Service database could be assigned to a case in the TR-DGU. The data are further limited because exact timing of prehospital TXA administration and dosages (TXA or fibrinogen concentrate) have not been documented. Personal correspondence with all participating Air Rescue bases revealed that the majority apply a single dose of $1 \mathrm{~g}$ of TXA during prehospital treatment. Patients were treated with TXA at the discretion of the emergency physician, not according to a standardized algorithm, representing another major weakness. In this context, base excess and overall transfusion rates were moderate, which might indicate that TXA was also administered to noncoagulopathic patients or patients without signs of active bleeding. Also, the subtype of colloid infusion is not specified in the databases. A further limitation is that the cause of death (e.g., bleeding, brain death) is not documented in the TRDGU; therefore, we cannot discern whether TXA was associated with reduced mortality due to haemorrhage.

Nevertheless, the present analysis represents the largest civilian study on prehospital TXA supplementation in trauma patients. The current European guidelines for management of bleeding and coagulopathy following major trauma recommend considering the administration of the first dose of TXA en route to the hospital. Since this is based on very limited evidence and extrapolated from the CRASH-2 trial, the authors graded this as a "very weak recommendation" (grade 2C) [10]. However, until further evidence emerges from ongoing prospective randomised controlled trials [32, 33], considering the existing literature on in-hospital administration, the results of the present study support the prehospital use of TXA in those trauma patients with severe injury with confirmed or suspected haemorrhagic shock.

\section{Conclusions}

In the present study of trauma patients, prehospital use of TXA was associated with prolonged time to death and significantly improved early survival, suggesting benefits of TXA on haemostatic resuscitation. Until further evidence emerges, the results support the use of TXA during prehospital treatment of severely injured patients.

\section{Key messages}

- Evidence from mature trauma systems on prehospital administration of TXA in civilian populations is not available.

- Prehospital use of TXA was associated with significantly longer time to death and significantly lower mortality rates at 6,12 and $24 \mathrm{~h}$.

- The most pronounced difference in mortality could be observed in those patients with a high propensity score reflecting severe injury load.

- The present data support the current recommendation to consider the first dose of TXA en route to the hospital. 


\section{Abbreviations}

ADAC: General German Automobile Club; AIS: Abbreviated Injury Scale; CPR: cardiopulmonary resuscitation; CRASH-2: Clinical Randomisation of an Antifibrinolytic in Significant Haemorrhage 2; ER: emergency room; FFP: fresh frozen plasma; GCS: Glasgow Coma Scale; DGU: Deutsche Gesellschaft für Unfallchirurgie; i.v.: intravenous; ICU: intensive care unit; INR: international normalized ratio; ISS: Injury Severity Score; LOS: length of stay; MATTERs: Military Application of Tranexamic Acid in Trauma Emergency Resuscitation; NACA: National Advisory Committee for Aeronautics; pRBC: packed red blood cells; PROPPR: Pragmatic Randomized Optimal Platelet and Plasma Ratios; PTI: prothrombin time index; RISC: Revised Injury Severity Classification; SBP: systolic blood pressure; SD: standard deviation; TBI: traumatic brain injury; TR: TraumaRegister; TXA: tranexamic acid.

\section{Competing interests}

The authors declare that they have no competing interests.

\section{Authors' contributions}

AW, MR and MG conceived the study, designed the trial, analysed the data, and drafted the manuscript. AW and MG undertook the statistical analysis and conducted literature searches. ABB contributed to the study design and analysis. AW and BB wrote the manuscript. All authors contributed substantially to manuscript revision. All authors read and approved the final manuscript.

\section{Acknowledgements}

We thank all participating ADAC Air Rescue Bases, the Committee on Emergency Medicine, Intensive Care and Trauma Management of the German Trauma Society (Sektion NIS) and all participating trauma centres (complete list at www.traumaregister.de). Committee on Emergency Medicine, Intensive Care and Trauma Management of the German Trauma Society (Sektion NIS)

\section{Author details}

'Department of Trauma and Orthopedic Surgery, University of Witten/ Herdecke, Cologne-Merheim Medical Center, Ostmerheimer Strasse 200, D-51109 Cologne, Germany. ${ }^{2}$ Institute for Research in Operative Medicine (IFOM), University of Witten/Herdecke, Ostmerheimer Strasse 200, D-51109 Cologne, Germany. ${ }^{3}$ Department of Anesthesiology and Intensive Care Medicine, University of Witten/Herdecke, Cologne-Merheim Medical Center, Ostmerheimer Strasse 200, D-51109 Cologne, Germany. ${ }^{4}$ Department of Medicine - ADAC Air Rescue Service (Subsidiary of the General German Automobile Club), Munich, Germany.

\section{Received: 29 December 2015 Accepted: 26 April 2016} Published online: 12 May 2016

\section{References}

1. Kauvar DS, Lefering R, Wade CE. Impact of hemorrhage on trauma outcome: an overview of epidemiology, clinical presentations, and therapeutic considerations. J Trauma. 2006;60(6 Suppl):S3-11.

2. Wafaisade $A$, Wutzler $S$, Lefering $R$, Tjardes $T$, Banerjee $M$, Paffrath $T$, et al. Drivers of acute coagulopathy after severe trauma: a multivariate analysis of 1987 patients. Emerg Med J. 2010;27:934-9.

3. Maegele $M$, Lefering $R$, Yucel $N$, Tjardes $T$, Rixen D, Paffrath $T$, et al. Early coagulopathy in multiple injury: an analysis from the German Trauma Registry on 8724 patients. Injury. 2007;38:298-304

4. Brohi K, Singh J, Heron M, Coats T. Acute traumatic coagulopathy. J Trauma. 2003;54:1127-30.

5. Holcomb JB, Tilley BC, Baraniuk S, Fox EE, Wade CE, Podbielski JM, et al. Transfusion of plasma, platelets, and red blood cells in a 1:1:1 vs a 1:1:2 ratio and mortality in patients with severe trauma: the PROPPR randomized clinical trial. JAMA. 2015;313:471-82

6. Wafaisade $A$, Lefering $R$, Maegele $M$, Lendemans S, Flohé S, Hussmann B, et al. Coagulation management of bleeding trauma patients is changing in German trauma centers: an analysis from the trauma registry of the German Society for Trauma Surgery. J Trauma Acute Care Surg. 2012;72:936-42.

7. Moore HB, Moore EE, Gonzalez E, Chapman MP, Chin TL, Silliman CC, et al. Hyperfibrinolysis, physiologic fibrinolysis, and fibrinolysis shutdown: the spectrum of postinjury fibrinolysis and relevance to antifibrinolytic therapy. J Trauma Acute Care Surg. 2014;77:811-7.
8. Shakur H, Roberts I, Bautista R, Caballero J, Coats T, Dewan Y, et al. Effects of tranexamic acid on death, vascular occlusive events, and blood transfusion in trauma patients with significant haemorrhage (CRASH-2): a randomised, placebo-controlled trial. Lancet. 2010;376:23-32.

9. Roberts I, Shakur H, Afolabi A, Brohi K, Coats T, Dewan Y, et al. The importance of early treatment with tranexamic acid in bleeding trauma patients: an exploratory analysis of the $\mathrm{CRASH}-2$ randomised controlled trial. Lancet. 2011;377:1096-101.e2.

10. Spahn DR, Bouillon B, Cerny V, Coats TJ, Duranteau J, Fernández-Mondéjar E, et al. Management of bleeding and coagulopathy following major trauma: an updated European guideline. Crit Care. 2013;17:R76.

11. Helm M, Haunstein B, Schlechtriemen T, Ruppert M, Lampl L, Gäßler M. $\left.\mathrm{EZ}-\mathrm{IO}{ }^{(}\right)$intraosseous device implementation in German Helicopter Emergency Medical Service. Resuscitation. 2015;88:43-7.

12. Weiss M, Bernoulli L, Zollinger A. The NACA scale: construct and predictive validity of the NACA scale for prehospital severity rating in trauma patients. Anaesthesist. 2001;50:150-4.

13. Scoring Study Committee of the German Society of Trauma Surgery. Trauma register of the German Society of Trauma Surgery [in German]. Unfallchirurg. 1994;97:230-7.

14. Baker SP, O'Neill B, Haddon W, Long WB. The injury severity score: a method for describing patients with multiple injuries and evaluating emergency care. J Trauma. 1974;14:187-96.

15. Gennarelli TA, Wodzin E. AIS 2005: a contemporary injury scale. Injury. 2006:37:1083-91.

16. Vincent $J$, de Mendonça A, Cantraine F, Moreno R, Takala J, Suter PM, et al. Use of the SOFA score to assess the incidence of organ dysfunction/failure in intensive care units: results of a multicenter, prospective study. Crit Care Med. 1998;26:1793-800.

17. Bone RC. Let's agree on terminology: definitions of sepsis. Crit Care Med. 1991;19:973-6.

18. Wagner C, Dati F. Thromboplastinzeit. In: Thomas L, editor. Labor und Diagnose: Indikation und Bewertung von Laborbefunden für die medizinische Diagnostik. Frankfurt, Germany: TH-Books; 2000. p. 613-6.

19. Holcomb JB, Weiskopf R, Champion H, Gould SA, Sauer RM, Brasel K, et al. Challenges to effective research in acute trauma resuscitation: consent and endpoints. Shock. 2011;35:107-13.

20. Jiménez J, Iribarren JL, Brouard M, Hernández D, Palmero S, Jiménez A, et al. Safety and effectiveness of two treatment regimes with tranexamic acid to minimize inflammatory response in elective cardiopulmonary bypass patients: a randomized double-blind, dose-dependent, phase IV clinical trial. J Cardiothorac Surg. 2011;6:138.

21. Ker K, Prieto-Merino D, Roberts I. Systematic review, meta-analysis and meta-regression of the effect of tranexamic acid on surgical blood loss. Br J Surg. 2013;100:1271-9.

22. Casati V, Romano A, Novelli E, D'Angelo A. Tranexamic acid for trauma. Lancet. 2010;376:1049-50. author reply 1050-1.

23. Morrison JJ, Dubose JJ, Rasmussen TE, Midwinter MJ. Military Application of Tranexamic Acid in Trauma Emergency Resuscitation (MATTERs) Study. Arch Surg. 2012;147:113-9.

24. Morrison JJ, Ross JD, Dubose JJ, Jansen JO, Midwinter MJ, Rasmussen TE. Association of cryoprecipitate and tranexamic acid with improved survival following wartime injury: findings from the MATTERs II Study. JAMA Surg. 2013;148:218-25.

25. Valle EJ, Allen CJ, Van Haren RM, Jouria JM, Li H, Livingstone AS, et al. Do all trauma patients benefit from tranexamic acid? J Trauma Acute Care Surg. 2014;76:1373-8.

26. Cole E, Davenport R, Willett K, Brohi K. Tranexamic acid use in severely injured civilian patients and the effects on outcomes: a prospective cohort study. Ann Surg. 2015;261:390-4.

27. Ausset S, Glassberg E, Nadler R, Sunde G, Cap AP, Hoffmann C, et al. Tranexamic acid as part of remote damage-control resuscitation in the prehospital setting: a critical appraisal of the medical literature and available alternatives. J Trauma Acute Care Surg. 2015:78(6 Suppl 1):S70-5.

28. Paudyal P, Smith J, Robinson M, South A, Higginson I, Reuben A, et al. Tranexamic acid in major trauma: implementation and evaluation across South West England. Eur J Emerg Med. doi:10.1097/ MEJ.0000000000000323.

29. Lipsky AM, Abramovich A, Nadler R, Feinstein U, Shaked G, Kreiss Y, et al. Tranexamic acid in the prehospital setting: Israel Defense Forces' initial experience. Injury. 2014;45:66-70. 
30. Benov A, Glassberg E, Nadler R, Gendler S, Erlich T, Bader T, et al. Role I trauma experience of the Israeli Defense Forces on the Syrian border. J Trauma Acute Care Surg. 2014;77(3 Suppl 2):S71-6.

31. Vu EN, Schlamp RS, Wand RT, Kleine-Deters GA, Vu MP, Tallon JM. Prehospital use of tranexamic acid for hemorrhagic shock in primary and secondary air medical evacuation. Air Med J. 2013:32:289-92.

32. Brown JB, Neal MD, Guyette FX, Peitzman AB, Billiar TR, Zuckerbraun BS, et al. Design of the Study of Tranexamic Acid during Air Medical Prehospita Transport (STAAMP) trial: addressing the knowledge gaps. Prehosp Emerg Care. 2015;19:79-86.

33. Mitra B, Mazur S, Cameron PA, Bernard S, Burns B, Smith A, et al. Tranexamic acid for trauma: filling the "GAP" in evidence. Emerg Med Australas. 2014;26:194-7

Submit your next manuscript to BioMed Central and we will help you at every step:

- We accept pre-submission inquiries

- Our selector tool helps you to find the most relevant journal

- We provide round the clock customer support

- Convenient online submission

- Thorough peer review

- Inclusion in PubMed and all major indexing services

- Maximum visibility for your research

Submit your manuscript at www.biomedcentral.com/submit 